\title{
Association Between the AI I8G Polymorphism of the OPRMI Gene and Suicidal Depression in a Large Cohort of Outpatients with Depression
}

\author{
Benedicte Nobile $\mathbb{D}^{1,2}$ \\ Emilie Olie ${ }^{1-3}$ \\ Nicolas Ramoz (iD) ${ }^{4}$ \\ Jonathan Dubois ${ }^{1,2}$ \\ Sebastien Guillaume ${ }^{1-3}$ \\ Philip Gorwood ${ }^{4}$ \\ Philippe Courtet ${ }^{\mathrm{I}-3}$ \\ 'Department of Emergency Psychiatry \\ and Acute Care, CHU Montpellier, \\ Montpellier, France; ${ }^{2}$ IGF, University of \\ Montpellier, CNRS, INSERM, Montpellier, \\ France; ${ }^{3}$ FondaMental Foundation, \\ Créteil, France; ${ }^{4}$ Inserm UMRSI266, \\ Institute of Psychiatry and Neuroscience \\ of Paris, Paris, France
}

\begin{abstract}
Background: Growing evidences suggest that depression with suicidal ideation (SI) could be a specific phenotype with its own characteristics. Moreover, opioid system deregulation might be implicated in suicidal behaviour (SB). The aim of this study was to determine whether the A118G polymorphism (rs1799971) in ORPMI (the gene encoding opioid receptor $\mathrm{mu} 1$ ) is associated with suicidal depression (ie, moderate to severe depression with SI) in a large cohort of outpatients with depression.
\end{abstract}

Methods: GENESE is a large, prospective, naturalistic cohort of French adult outpatients with depression (DSM-IV criteria), treated and followed for 6 weeks. Depression severity was assessed with the Hospital Anxiety and Depression Scale (HADS), and SI with the suicidal item of the Montgomery-Åsberg Depression Rating Scale (MADRS-SI). From this cohort, patients with moderate or severe depression (HADS-D subscale score $>11$ ) were selected and classified as without SI (MADRS-SI $<2$ ), or with SI (MADRS-SI $\geq 2$ ).

Results: The AA/AG genotypes of the A118G polymorphism were significantly associated with suicidal depression in the non-adjusted $(\mathrm{OR}=2.32,95 \% \mathrm{CI}=[1.28 ; 4.18]$; $p$-value $=$ $0.005)$ and in the adjusted models $(\mathrm{OR}=2.54,95 \% \mathrm{CI}=[1.35 ; 4.78]$; $p$-value $=0.004)$.

Conclusion: Outpatients with depression harbouring the A allele are at higher risk of SI (and possibly SB) than those carrying the $G$ allele. More studies are needed to better understand the link between this polymorphism and SB.

Keywords: suicide, suicidal ideation, opioid system, A118G, OPRM1

\section{Introduction}

Suicide is a major public health problem. Most studies on suicidal behaviour (SB) have focused on suicide and suicide attempts (SA). Conversely, suicidal ideation (SI) too often escapes the attention of suicide prevention research and clinical treatments. ${ }^{1}$ SI physiopathology may be different from that of $\mathrm{SB}^{2}$ because subjects experiencing SI do not systematically attempt suicide and some suicide completers have no past history of SB. ${ }^{3,4}$ Yet, SI is the third most potent predictor of future death by suicide. ${ }^{5}$ One-third of patients with SI will attempt suicide, and among them $60 \%$ within the year following SI onset. ${ }^{3,6,7}$ It can be hypothesized that reducing SI may help to prevent SB.

$\mathrm{SI}$ is frequent in patients with major depressive episode (from 40 to $75 \%$ ). ${ }^{8}$ Growing evidence suggests that suicidal depression (ie, depression with SI) could be a specific phenotype of depression. Compared with depressed patients without SI, suicidal depressed patients are characterized by more severe clinical features
Correspondence: Benedicte Nobile Email benedicte.nobile@gmail.com 
(eg, greater depressive symptom severity and number of depressive episodes, more frequent history of SA) $)^{9-11}$ and worse response to antidepressant treatment. They are also less likely to achieve remission. ${ }^{12}$ Although SI and depression severity are associated, their progression is not overlapping. For instance, in a cohort of patients with severe depression, Khan et $\mathrm{al}^{13}$ found that SI reduction preceded depression improvement and that the magnitude of SI reduction was larger than that of depression reduction. These results suggest that contrary to current beliefs, SI decrease may not be a consequence of depression improvement. This hypothesis is sustained by a study demonstrating that SI reduction by ketamine administration is only partially linked to the reduction of depressive symptomatology. ${ }^{14}$ On the other hand, Seo et al ${ }^{15}$ showed that in $46 \%$ of patients with pre-existing SI during depression treatment, SI persisted despite the improvement of the depressive symptomatology. These findings suggest that the trajectories of SI and depression might be separated, while somehow related. ${ }^{16}$ Indeed, depressive symptomatology profiles are different in patients with and without SI. ${ }^{10,17,18}$

The opioid system might be involved in SB physiopathology. ${ }^{19}$ It has been shown that consumption of opiate analgesics is higher in patients with suicidal depression than in those without suicidal depression and in healthy controls, independently of their health status. ${ }^{20,21}$ Furthermore, the density of mu-opioid receptors (MOR) in prefrontal cortex and nucleus caudate is higher in brain of suicide victims. ${ }^{22,23}$ Recent randomized controlled trials showed a significant reduction of SI in patients with depression on buprenorphine (a partial mu agonist and kappa antagonist) than in those on placebo, suggesting the usefulness of opioid drugs in suicide prevention. $^{24,25}$ The A118G (rs1799971) variant in the first exon of OPRMI (opioid mu receptor gene) is a functional single nucleotide polymorphism (SNP) in the opioid system. The $G$ allele (recessive) of this SNP results in an amino-acid change, resulting in a change of MOR expression and function. ${ }^{27,28}$ This SNP has been associated with pain regulation and sensitivity to social rejection, which are known to play a role in $\mathrm{SB} .{ }^{29-32}$ For instance, $G$ allele was associated with a greater sensitivity to social pain ${ }^{32-34}$ and with the occurrence of a depressive episode following a rejection event (but not other stressful life events). ${ }^{35}$ Few studies are available concerning the association between this SNP and SB. One study found that AA genotype was associated with complete suicide. ${ }^{36}$
Our group reported that this SNP was involved in treatment emergent SI (TESI) at antidepressant onset (AA genotype was significantly associated with TESI), independently of the depressive symptomatology course. ${ }^{36}$ Genetics studies in SB are still scarce and even if some candidate genes have been found, these studies need to be replicated and more genes have to be explored. ${ }^{37}$

We recently showed that suicidal depressed patients were different from non-suicidal patients in this cohort (eg, more severe clinical features, different course of depression and less response to treatment). ${ }^{10}$ Thus, we decided to assess whether the A118G SNP was associated with the phenotype of suicidal depression. Indeed, considering our precedent results, we hypothesized that patients with a AA genotype could be more prone to have a suicidal depression.

\section{Methods}

\section{Participants}

GENESE is a large, prospective, naturalistic cohort of 3566 French outpatients with a major depressive episode (diagnosis according to the DSM-IV criteria) treated with tianeptine. Tianeptine dose was chosen by their general practitioner (GP) or psychiatrist, and ranged between 12.5 and $37.5 \mathrm{mg} / \mathrm{day}$, according to the prescription recommendations. The same physician (GP or psychiatrist) followed the patients for at least 6 weeks after treatment initiation. Demographic data, history of major depressive disorder and of lifetime SA were collected by the physician at the first visit (ie, treatment initiation). Non-inclusion criteria were: age $<18$ years, non-Caucasian ethnicity, alcohol and substance dependence, or any psychiatric pathology from axis I other than current major depressive episode.

The study was performed according to the French regulatory guidelines and the current codes of Good Clinical Practice. Each patient was informed about the aims and procedures of the study and provided a written, signed consent. The study protocol was submitted to and approved by local independent ethics committees (Comité de Protection des Personnes CPP Ile de France XI (CPPIDF11), Centre Hospitalier Intercommunal CHI Poissy Saint-Germain, Saint Germain en Laye, reference no. 08042).

\section{Clinical Assessments}

Hetero-evaluations were performed at the first visit and at the follow-up end. Auto-evaluations were performed at 
the first visit, week 2 and week 4 , and at the follow-up end. Our priority was to use self-reported evaluations of SI and depression because patients are more likely to disclose SI in self-reported measures than to a clinician. Moreover, self-report seems to be a good predictor of future SA. ${ }^{38-40}$ Depression severity was assessed with the validated French version of the Hospital Anxiety and Depression Scale (HADS). This scale has a good performance for assessing depression severity in both psychiatric and primary care patients and a good sensitivity to changes. ${ }^{41}$ Most factor analyses found a twofactor solution in accordance with the Anxiety (HADS-A) and Depression (HADS-D) subscales. This scale was chosen for its simplicity of use and understanding and for its good psychometric properties, which have been demonstrated also in outpatient groups. ${ }^{42}$ As no specific scale has been univocally proposed for clinical practice or for clinical research to assess SI, here SI was evaluated using the suicidal item of the self-rated MontgomeryÅsberg Depression Rating Scale (MADRS-SI) completed by patients. The ratings range from 0 to $6: 0$ to 1 ) enjoys life or takes it as it comes; 2 to 3) weary of life, only fleeting suicidal thoughts; 4 to 5) probably better off dead, suicidal thoughts are common, and suicide is considered as a possible solution, but without specific plans or intention; and 6) explicit plans for suicide when there is an opportunity, active preparations for suicide. It has been demonstrated that a single suicide item from a depression rating scale, either clinician-rated or selfreported, is a valid approach to assess SI, compared with Beck's scale. ${ }^{43}$ This method was used in large clinical studies, such as the $\mathrm{STAR} * \mathrm{D},{ }^{44}$ and also in more recent studies. $^{36}$

Plutchik's Impulsivity Questionnaire ${ }^{45}$ and the sleep item of the self-rated MADRS were used to assess impulsivity and sleep quality, respectively.

\section{Single Nucleotide Polymorphism and Genotyping}

The SNP A118G of OPRM1 was chosen on the basis of two criteria: 1) SNP of the opioid system that was previously reported as associated with suicide and depression; 2) minor allele frequencies above 5\%. The Hardy-Weinberg equilibrium was respected.

DNA was collected at baseline by buccal swab. Genotyping was performed with a $5^{\prime}$ exonuclease assay (TaqMan, Life Technologies). Assay products were run on an applied Biosystem 7900HT Fast Real-Time PCR System (Life Technologies).

The success rate of SNP genotyping in our population was $95 \%$. In each 96-well plate, four DNA samples were assessed in replicate (duplicate) to measure the reproducibility rate. The plate was genotyped again When a discrepancy in one of these replicates was observed. Overall, the replication rate was $99.9 \%$ for all genotyping runs.

\section{Definition of Suicidal Depression Phenotypes}

Only the scores of self-administered questionnaires were used for the analyses. Among the 3566 patients of this cohort, A118G genotyping could be performed in 2801 (78.5\%). Among the patients with genotyping data, patients with moderate to severe depression at baseline were selected $(\mathrm{N}=2012,71.8 \%)$ according to the French High Authority of Health definition (ie, HADS-D subscale score > 11). The MADRS-SI score was used to classify patients as having suicidal depression (MADRS-SI score $\geq 2$ ) or non-suicidal depression (ie, MADRS-SI score $<2$ ).

\section{Statistical Analysis}

Categorical variables were presented as percentages, and quantitative variables as means with standard deviation (SD). Demographic and clinical characteristics in patients with non-suicidal depression and with suicidal depression were compared using a univariate logistic regression model.

To study the association between genotype and then allele (separately) and depression phenotype, firstly a univariate logistic regression model was used to estimate the odds-ratios (OR) and their 95\% confidence interval (95\% CI) in crude association. Then, baseline sociodemographic and clinical variables associated with suicidal depression at $\mathrm{p}<0.10$ were included in the logistic regression models to estimate the adjusted OR and $95 \%$ CI. For these models, depression phenotype (suicidal depression vs non-suicidal depression) was defined as the outcome and genotypes were defined as "exposure". Genotypes were coded as follows: $\mathrm{GG}=0 ; \mathrm{AG}=1$ and $\mathrm{AA}=2$ and regrouped genotypes as: $\mathrm{AG}$ or $\mathrm{GG}=1 ; \mathrm{AA}=2$ on one hand and $\mathrm{AA}$ or $\mathrm{AG}=1 ; \mathrm{GG}=2$ on the other hand.

Sensitivity analyses in which patients with lifetime SA were removed were performed using the same models.

The significance level was set at $\mathrm{P}<0.05$. Analyses were performed using the SPSS statistical software 
(version 26; IBM SPSS Statistics for Windows. Armonk, NY: IBM Corp).

\section{Results}

\section{Baseline Characteristics}

The study sample included 2012 depressed patients with a mean age of 49 years; 799 (39.7\%) were men. Comparison of the baseline characteristics of patients with non-suicidal depression $(\mathrm{n}=298 ; 14.8 \%)$ and suicidal depression $(\mathrm{n}=1714 ; 85.2)$ (Table 1$)$ showed that sociodemographic characteristics were comparable between groups, except for professional status (suicidal patients were less active, $p$-value $=0.0004$ ). Compared with the non-suicidal depression group, the number of major depressive episodes ( $p$-value $=0.01$ ), and the percentage of patients with associated treatment $(p$-value $<0.001)$ and of patients who needed a change of antidepressant treatment (vs initiation of a new one) for the current episode ( $p$-value $=0.01)$ were higher in the suicidal depression group. Moreover, the baseline clinical characteristics were more severe in patients with suicidal depression than in those with non-suicidal depression: higher percentage of patients with history of lifetime SA ( $p$-value $<0.001$ ), higher HADS total score and sub-scores ( $p$-value $<$ $0.001)$, higher impulsivity score $(p$-value $<0.001)$ and more sleep disturbances ( $p$-value $<0.001)$.

\section{Association Between the AII8G SNP and Suicidal Depression}

The AA and AG genotypes of the A118G SNP were significantly associated with suicidal depression (model 0: OR= $2.36,95 \% \mathrm{CI}=[1.30 ; 4.29], p$-value $=0.02 ; \mathrm{OR}=2.19,95 \%$ $\mathrm{CI}=[1.17 ; 4.11], p$-value $=0.02$, respectively; Table 2 ). This association remained significant after adjusting for potential confounders (professional activity, lifetime SA, HADS total score, impulsivity score, MADRS-sleep score, associated treatment and instauration/change of treatment) for both genotypes (model 1: $\mathrm{OR}=2.51,95 \% \mathrm{CI}=[1.32 ; 4.74], p$-value $=$ $0.02 ; \mathrm{OR}=2.62,95 \% \mathrm{CI}=[1.34 ; 5.14], \quad p$-value $=0.02$, respectively; Table 2). The multivariate logistic regression analysis did not include the number of depressive episodes because this was associated with both suicidal depression and SNP genotype.

After grouping genotypes (AA/AG versus GG) (Table 2), the AA/AG genotypes were significantly associated with suicidal depression in the non-adjusted model $(\mathrm{OR}=2.32, \quad 95 \% \quad \mathrm{CI}=[1.28 ; 4.18] ; \quad p$-value $=0.005 ;$ model 0$)$ and also in the adjusted model $(\mathrm{OR}=2.54$, $95 \% \mathrm{CI}=[1.35 ; 4.78] ; p$-value $=0.004 ;$ model 1$)$.

Finally, comparison of the A and $\mathrm{G}$ allele frequency in the two patient groups (Table 3) showed that the A allele was associated with suicidal depression in the unadjusted model $(\mathrm{OR}=1.27,95 \% \mathrm{CI}=[1.01 ; 1.59] ; p$-value $=0.04$; model 0 ), but not in the adjusted model.

\section{Association Between AII8G and SA During the Follow-Up}

During the follow-up, eight SA (0.4\%) were reported. None of these patients harboured the GG genotype (data not shown).

\section{Sensitivity Analysis}

When removing patients with lifetime history of SA, the results did not change (Tables 4 and 5). The AG/AA genotypes remained significantly associated with suicidal depression $(\mathrm{OR}=2.77,95 \% \mathrm{CI}=[1.49 ; 5.13] ; p$-value $=$ 0.001 ; model 0$)$, even after adjusting for potential confounders $(\mathrm{OR}=2.88,95 \% \mathrm{CI}=[1.50 ; 5.51] ; p$-value $=$ 0.001 ; model 1).

\section{Discussion}

This is the first study to assess the association between the SNP A118G in OPRM1 and suicidal depression (ie, moderate to severe depression with SI) in a large cohort of depressed outpatients. We found that genotypes with the A allele (dominant) were significantly associated with suicidal depression, with a stronger relation after adjusting for potential confounders. These results did not change after removing from the analysis patients with lifetime SA (sensitivity analysis). In the same cohort, we previously reported that the A allele is associated with higher risk of treatment-emergent SI at antidepressant onset. ${ }^{36}$ Previously, a post-mortem study reported that the AA genotype is associated with a 1.7 -fold higher risk of completed suicide. ${ }^{35}$ Therefore, we could hypothesize that the G allele (recessive) protects from SI and complete suicide.

Interestingly, the presence of the $G$ allele leads to a change of MOR expression and function. However, more studies are needed to better understand the related biological and behavioural consequences of this change. ${ }^{26}$ Some studies in healthy subjects found that the levels of pro-inflammatory cytokines are significantly lower in $\mathrm{G}$ allele carriers (correlated with higher score of healthrelated quality of life) and that cortisol levels in response 
Table I Association Between Baseline Sociodemographic and Clinical Data and Suicidal Depression

\begin{tabular}{|c|c|c|c|c|c|}
\hline \multirow[b]{4}{*}{ Variables } & \multicolumn{4}{|c|}{ Suicidal Depression } & \multirow[b]{4}{*}{$P$-value } \\
\hline & \multicolumn{2}{|c|}{ No } & \multicolumn{2}{|c|}{ Yes } & \\
\hline & \multicolumn{2}{|c|}{$N=298$} & \multicolumn{2}{|c|}{$N=1714$} & \\
\hline & $\mathbf{n}$ & $\%$ & $\mathbf{n}$ & $\%$ & \\
\hline Sex & & & & & 0.86 \\
\hline Men & 117 & 39.3 & 682 & 39.8 & \\
\hline Women & 181 & 60.7 & 1032 & 60.2 & \\
\hline Age (years) & \multicolumn{2}{|c|}{48.49 (14.92) } & \multicolumn{2}{|c|}{$49.96(14.67)$} & 0.11 \\
\hline Marital Status & & & & & 0.07 \\
\hline Single & 53 & 17.8 & 314 & 18.4 & \\
\hline Married & 190 & 64 & 971 & 56.8 & \\
\hline Divorced & 36 & 12.1 & 296 & 17.3 & \\
\hline Widower & 18 & 6.1 & 129 & 7.5 & \\
\hline Study level & & & & & 0.06 \\
\hline Lower secondary school & 113 & 38.6 & 775 & 45.5 & \\
\hline Upper secondary school & 80 & 27.3 & 446 & 26.2 & \\
\hline University & 100 & 34.1 & 484 & 28.4 & \\
\hline Professional activity & & & & & 0.004 \\
\hline Working & 184 & 62.6 & 881 & 51.8 & \\
\hline Unemployment & 19 & 6.5 & 175 & 10.3 & \\
\hline Retired & 58 & 19.7 & 372 & 21.9 & \\
\hline Other & 33 & 11.2 & 272 & 16 & \\
\hline MDE duration & & & & & 0.07 \\
\hline$<2$ months & 114 & 39 & 550 & 32.8 & \\
\hline$[2 ; 6]$ months & 120 & 41.1 & 711 & 42.4 & \\
\hline$>6$ months & 58 & 19.9 & 414 & 24.7 & \\
\hline First MDE & & & & & 0.002 \\
\hline Yes & 190 & 64 & 926 & 54.2 & \\
\hline No & 107 & 36 & 784 & 45.8 & \\
\hline Number of MDE & \multicolumn{2}{|c|}{$2.26(1.37)$} & \multicolumn{2}{|c|}{$2.88(2.53)$} & 0.01 \\
\hline Lifetime cumulated MDE duration (weeks) & \multicolumn{2}{|c|}{$30.68(25.38)$} & \multicolumn{2}{|c|}{34.99 (28.78) } & 0.16 \\
\hline Age at first MDE (years) & \multicolumn{2}{|c|}{$36.58(14.79)$} & \multicolumn{2}{|c|}{$35.74(13.70)$} & 0.56 \\
\hline HADS-A & \multicolumn{2}{|c|}{$13.53(3.35)$} & \multicolumn{2}{|c|}{$14.59(3.4 I)$} & $<0.001$ \\
\hline HADS-D & \multicolumn{2}{|c|}{$|4.7|(2.34)$} & \multicolumn{2}{|c|}{$15.80(2.63)$} & $<0.001$ \\
\hline HADS total score & \multicolumn{2}{|c|}{$28.24(4.69)$} & \multicolumn{2}{|c|}{$30.40(4.92)$} & $<0.001$ \\
\hline Impulsivity score & \multicolumn{2}{|c|}{$35.93(5.75)$} & \multicolumn{2}{|c|}{$37.41(6.38)$} & $<0.001$ \\
\hline MADRS-sleep & & & & & $<0.001$ \\
\hline Lifetime suicide attempts & & & & & $<0.001$ \\
\hline Yes & 9 & 3.1 & 219 & 13.1 & \\
\hline No & 280 & 96.9 & 1447 & 86.9 & \\
\hline Associated treatment & & & & & $<0.001$ \\
\hline Yes & 143 & 48 & 1013 & 59.1 & \\
\hline No & 155 & 52 & 701 & 40.9 & \\
\hline Treatment instauration & & & & & 0.01 \\
\hline Yes & 255 & 85.9 & 1350 & 79.6 & \\
\hline No & 42 & 14.1 & 346 & 20.4 & \\
\hline
\end{tabular}

Note: Bold value represent significant results ( $p$-value $<0.05)$.

Abbreviations: HADS, Hospital Anxiety and Depression Scale; HADS-A, HADS-Anxiety; HADS-D, HADS-Depression; MADRS, Montgomery-Åsberg Depression Rating Scale; MDE, major depressive episode. 
Table 2 Association Between ORPMI AII8G SNP Genotype and Suicidal Depression

\begin{tabular}{|c|c|c|c|c|c|c|c|c|}
\hline & \multicolumn{4}{|c|}{ Suicidal Depression } & \multicolumn{2}{|c|}{ Model 0} & \multirow{3}{*}{$\begin{array}{c}\text { Model I } \\
\text { OR }[95 \% \mathrm{Cl}]\end{array}$} & \multirow{3}{*}{$p$-value } \\
\hline & \multicolumn{2}{|c|}{$\begin{array}{c}\text { No } \\
\mathbf{N}=\mathbf{2 9 8}\end{array}$} & \multicolumn{2}{|c|}{$\begin{array}{c}\text { Yes } \\
N=1714\end{array}$} & \multirow[t]{2}{*}{ OR $[95 \% \mathrm{Cl}]$} & \multirow[t]{2}{*}{ p-value } & & \\
\hline & $\mathbf{n}$ & $\%$ & $\mathbf{n}$ & $\%$ & & & & \\
\hline AlI8G & & & & & & & & \\
\hline GG & 16 & 5.4 & 41 & 2.4 & $I^{*}$ & 0.02 & $\mathrm{I} *$ & 0.02 \\
\hline AG & 77 & 25.8 & 433 & 25.3 & $2.19[1.17 ; 4.11]$ & & $2.62[1.34 ; 5.14]$ & \\
\hline AA & 205 & 68.8 & 1240 & 72.3 & $2.36[1.30 ; 4.29]$ & & $2.51[1.32 ; 4.74]$ & \\
\hline AlI8G & & & & & & & & \\
\hline $\mathrm{AA} / \mathrm{AG}$ & 282 & 94.6 & 1673 & 97.6 & $2.32[1.28 ; 4.18]$ & 0.005 & $2.54[1.35 ; 4.78]$ & 0.004 \\
\hline GG & 16 & 5.4 & 41 & 2.4 & $I^{*}$ & & I* & \\
\hline
\end{tabular}

Notes: Model 0: crude association. Model I: adjusted for professional activity, lifetime SA, baseline HADS total score, impulsivity score and MADRS-sleep, associated treatment and instauration/change of treatment. *Means that this genotype was taken as reference for binary logistic regression. Bold value represent significant results $(p$-value < 0.05).

Table 3 Association Between ORPMI AII8G SNP Allele and Suicidal Depression

\begin{tabular}{|c|c|c|c|c|c|c|c|c|}
\hline & \multicolumn{4}{|c|}{ Suicidal Depression } & \multicolumn{2}{|c|}{ Model 0} & \multirow{3}{*}{$\begin{array}{c}\text { Model I } \\
\text { OR }[95 \% \mathrm{CI}]\end{array}$} & \multirow{3}{*}{$p$-value } \\
\hline & \multicolumn{2}{|c|}{$\begin{array}{c}\text { No } \\
\mathbf{N}=\mathbf{2 9 8}\end{array}$} & \multicolumn{2}{|c|}{$\begin{array}{c}\text { Yes } \\
N=1714\end{array}$} & \multirow[t]{2}{*}{ OR $[95 \% \mathrm{Cl}]$} & \multirow[t]{2}{*}{$p$-value } & & \\
\hline & $\mathbf{n}$ & $\%$ & $\mathbf{n}$ & $\%$ & & & & \\
\hline AII8G & & & & & & & & \\
\hline G & 109 & 18.3 & 515 & 15 & I* & 0.04 & & 0.16 \\
\hline A & 487 & 81.7 & 2913 & 85 & 1.27 [1.01; 1.59] & & & \\
\hline
\end{tabular}

Notes: Model 0: crude association. Model I: adjusted for professional activity, lifetime SA, baseline HADS total score, impulsivity score and MADRS-sleep, associated treatment and instauration/change of treatment. *Means that this allele was taken as reference for binary logistic regression. Bold value represent significant results $(p$-value $<0.05)$.

to stress are lower in women harbouring the $\mathrm{G}$ allele. ${ }^{46,47}$ This finding is very interesting because cortisol stress response and inflammatory system are upregulated in SB. ${ }^{48}$ Moreover, the $\mathrm{G}$ allele has been associated with greater sensibility to social rejection, ${ }^{31-33}$ higher risk of depressive episodes following social rejection (but not other type of negative event), ${ }^{34}$ and greater social capacity (eg, higher pleasure and engagement in social interactions). ${ }^{29,49}$ On the basis of these findings, it could be hypothesized that carriers of the $G$ allele are more sensitive to social interactions, whatever their valence (rejection or support). Consequently, they could be more prone to develop social support, a protective factor against SB. ${ }^{50}$ Unfortunately, as we did not assess social support and recent social negative events in our cohort, we could not test this hypothesis.

Our study has some limitations. First, we assessed SI with a single item of a depression severity scale, although this is considered a valid approach to assess SI. ${ }^{43}$ Second, we did not assess childhood trauma, social support and recent social events. It could have been interesting to evaluate the link between the A118G SNP, suicidal depression and childhood trauma and/or social background. Finally, due to the low number of SA during the follow-up $(\mathrm{N}=8)$, it was impossible to investigate the link between $\mathrm{SA}$ and genotype. Nevertheless, it is interesting that all SA were made by patients carrying the A allele. Our study has also strengths. Indeed, we used a large cohort of depressed outpatients (more than 2000 patients) who were recruited by GPs or psychiatrists throughout France. Therefore, they are representative of patients from "real life" situations. Then, we adjusted our analyses for a large number of potential confounders, and performed sensitivity analyses to strengthen the validity of our results. Finally, our study adds significant results in the genetic of SB. 
Table 4 Baseline Sociodemographic and Clinical Data in Patients with and without Suicidal Depression After Removal of Patients with Lifetime SA

\begin{tabular}{|c|c|c|c|c|c|}
\hline \multirow[b]{4}{*}{ Variables } & \multicolumn{4}{|c|}{ Suicidal Depression } & \multirow[b]{4}{*}{$P$-value } \\
\hline & \multicolumn{2}{|c|}{ No } & \multicolumn{2}{|c|}{ Yes } & \\
\hline & \multicolumn{2}{|c|}{$N=\mathbf{2 8 0}$} & \multicolumn{2}{|c|}{$N=1447$} & \\
\hline & $\mathbf{n}$ & $\%$ & $\mathbf{n}$ & $\%$ & \\
\hline Sex & & & & & 0.40 \\
\hline Men & 108 & 38.6 & 597 & 41.3 & \\
\hline Women & 172 & 61.4 & 850 & 58.7 & \\
\hline Age (years) & \multicolumn{2}{|c|}{$48.54(14.97)$} & \multicolumn{2}{|c|}{$50.39(14.94)$} & 0.06 \\
\hline Marital Status & & & & & 0.22 \\
\hline Single & 47 & 16.8 & 254 & 17.6 & \\
\hline Married & 181 & 64.9 & 849 & 58.8 & \\
\hline Divorced & 34 & 12.2 & 224 & 15.5 & \\
\hline Widower & 17 & 6.1 & 117 & 8.1 & \\
\hline Study level & & & & & 0.21 \\
\hline Lower secondary school & 104 & 37.8 & 625 & 43.4 & \\
\hline Upper secondary school & 77 & 28 & 383 & 26.6 & \\
\hline University & 94 & 34.2 & 433 & 30 & \\
\hline Professional activity & & & & & 0.05 \\
\hline Working & 173 & 62.7 & 773 & 53.8 & \\
\hline Unemployment & 18 & 6.5 & 127 & 8.8 & \\
\hline Retired & 56 & 20.3 & 335 & 23.3 & \\
\hline Other & 29 & 10.5 & 201 & 14 & \\
\hline MDE duration & & & & & 0.18 \\
\hline$<2$ months & 108 & 39.3 & 478 & 33.8 & \\
\hline$[2 ; 6]$ months & 113 & 41.1 & 611 & 43.2 & \\
\hline$>6$ months & 54 & 19.6 & 326 & 23 & \\
\hline First MDE & & & & & 0.12 \\
\hline Yes & 180 & 64.5 & 862 & 59.6 & \\
\hline No & 99 & 35.5 & 585 & 40.4 & \\
\hline Number of MDE & \multicolumn{2}{|c|}{$2.27(1.40)$} & \multicolumn{2}{|c|}{$2.49(1.97)$} & 0.27 \\
\hline Lifetime cumulated MDE duration (weeks) & \multicolumn{2}{|c|}{$28.73(20.35)$} & \multicolumn{2}{|c|}{$32.31(26.89)$} & 0.23 \\
\hline Age at first MDE (years) & \multicolumn{2}{|c|}{$37.03(15.05)$} & \multicolumn{2}{|c|}{$37.66(14.06)$} & 0.69 \\
\hline HADS-A & \multicolumn{2}{|c|}{$13.58(3.34)$} & \multicolumn{2}{|c|}{$14.55(3.40)$} & $<0.001$ \\
\hline HADS-D & \multicolumn{2}{|c|}{$14.76(2.36)$} & \multicolumn{2}{|c|}{$15.79(2.65)$} & $<0.001$ \\
\hline HADS total score & \multicolumn{2}{|c|}{$28.34(4.68)$} & \multicolumn{2}{|c|}{$30.34(4.91)$} & $<0.001$ \\
\hline Impulsivity score & \multicolumn{2}{|c|}{$35.97(5.68)$} & \multicolumn{2}{|c|}{$37.22(6.34)$} & 0.002 \\
\hline MADRS-sleep & \multicolumn{2}{|c|}{$3.15(1.61)$} & \multicolumn{2}{|c|}{$3.87(1.37)$} & $<0.001$ \\
\hline Associated treatment & & & & & 0.02 \\
\hline Yes & 138 & 49.3 & 826 & 57.1 & \\
\hline No & 142 & 50.7 & 621 & 42.9 & \\
\hline Treatment instauration & & & & & 0.09 \\
\hline Yes & 242 & 86.4 & 1181 & 82.3 & \\
\hline No & 38 & 13.6 & 254 & 17.7 & \\
\hline
\end{tabular}

Note: Bold value represent significant results $(p$-value $<0.05)$. 
Table 5 Association Between ORPMI AII8G SNP Genotype and Suicidal Depression After Removal of Patients with Lifetime SA

\begin{tabular}{|c|c|c|c|c|c|c|c|c|}
\hline & \multicolumn{4}{|c|}{ Suicidal Depression } & \multicolumn{2}{|c|}{ Model 0} & \multirow{3}{*}{$\begin{array}{c}\text { Model I } \\
\text { OR }[95 \% \mathrm{CI}]\end{array}$} & \multirow{3}{*}{$p$-value } \\
\hline & \multicolumn{2}{|c|}{$\begin{array}{c}\text { No } \\
\mathbf{N}=\mathbf{2 8 0}\end{array}$} & \multicolumn{2}{|c|}{$\begin{array}{c}\text { Yes } \\
N=1447\end{array}$} & \multirow[t]{2}{*}{ OR [95\% Cl] } & \multirow[t]{2}{*}{$p$-value } & & \\
\hline & $\mathbf{n}$ & $\%$ & $\mathbf{n}$ & $\%$ & & & & \\
\hline AII8G & & & & & & & & \\
\hline GG & 16 & 5.7 & 31 & 2.1 & $I^{*}$ & 0.005 & $I^{*}$ & 0.005 \\
\hline AG & 68 & 24.3 & 372 & 25.7 & $2.82[1.47 ; 5.44]$ & & $3.07[1.54 ; 6.12]$ & \\
\hline AA & 196 & 70 & 1044 & 72.1 & $2.75[1.47 ; 5.12]$ & & $2.8 \mathrm{I}[\mathrm{I} .46 ; 5.4 \mathrm{I}]$ & \\
\hline AII8G & & & & & & & & \\
\hline AA/AG & 264 & 94.3 & 1416 & 97.9 & $2.77[1.49 ; 5.13]$ & 0.001 & $2.88[1.50 ; 5.51]$ & 0.001 \\
\hline GG & 16 & 5.7 & 31 & 2.1 & $I^{*}$ & & $I^{*}$ & \\
\hline
\end{tabular}

Notes: Model 0: crude association. Model I: adjusted for age, professional activity, baseline HADS total score, impulsivity score and MADRS-sleep, associated treatment and instauration/change of treatment. *Means that this genotype was taken as reference for binary logistic regression. Bold value represent significant results $(p$-value $<0.05)$.

Indeed, genetic studies on SB and especially on SI are still scarce (even more in the French population). Further studies are needed to better understand physiopathology of SB and propose specific therapeutics to suicidal patients.

In conclusion, we found that the $\mathrm{AG} / \mathrm{AA}$ genotypes from the SNP A118G are associated with suicidal depression. It seems that the GG genotype might protect against suicidal depression. More studies are needed to better understand the link between this SNP and SB, by taking into account also the social background.

\section{Data Sharing Statement}

Due to ethical and legal restrictions, data involving clinical participants cannot be made publicly available.

\section{Acknowledgments}

The present work was supported by a research grant from Servier, who had no involvement in the design, organization, analysis, or preparation for publication of the study.

\section{Author Contributions}

All authors made a significant contribution to the work reported, whether that is in the conception, study design, execution, acquisition of data, analysis and interpretation, or in all these areas; took part in drafting, revising or critically reviewing the article; gave final approval of the version to be published; have agreed on the journal to which the article has been submitted; and agree to be accountable for all aspects of the work.

\section{Disclosure}

The authors have interests in relation with one or more organization that could be perceived as a possible conflict of interest in the context of the subject of this manuscript. The relationships are summarized as follows. Benedicte Nobile, Nicolas Ramoz, Emilie Olié and Jonathan Dubois report no financial relationships with commercial interests. Sebastien Guillaume received honoraria or research or educational conference grants from Bristol-Myers Squibb, Otsuka, Servier, Lundbeck, AstraZeneca and Janssen. Philip Gorwood reports no shares; has paid positions at University of Paris Descartes \& Hospital Sainte-Anne; is on the advisory board at AstraZeneca, Janssen, Servier, and Wyeth; reports personal fees from GSK, Janssen, Lundbeck, Otsuka, and SAGE, outside the submitted work. Philippe Courtet reports no shares; has paid positions at University of Montpellier \& CHU Montpellier; is on the advisory board at Servier; reports grants and/or personal fees from Janssen, Exeltis, Pfizer, Otsuka, and Lundbeck, outside the submitted work. The authors report no other conflicts of interest in this work.

\section{References}

1. Jobes DA, Joiner TE. Reflections on suicidal ideation. Crisis. 2019;40 (4):227-230. doi:10.1027/0227-5910/a000615

2. Klonsky ED, Saffer BY, Bryan CJ. Ideation-to-action theories of suicide: a conceptual and empirical update. Curr Opin Psychol. 2018;22:38-43.

3. Glenn CR, Nock MK. Improving the short-term prediction of suicidal behavior. Am J Prev Med. 2014;47(3 Suppl 2):S176-S180. doi:10.1016/j.amepre.2014.06.004

4. Busch KA, Fawcett J, Jacobs DG. Clinical correlates of inpatient suicide. J Clin Psychiatry. 2003;64(1):14-19. doi:10.4088/JCP. v64n0105 
5. Franklin JC, Ribeiro JD, Fox KR, et al. Risk factors for suicidal thoughts and behaviors: a meta-analysis of 50 years of research. Psychol Bull. 2017;143(2):187-232. doi:10.1037/bul0000084

6. Nock MK, Borges G, Bromet EJ, et al. Cross-national prevalence and risk factors for suicidal ideation, plans, and attempts. Br J Psychiatry. 2008;192:98-105. doi:10.1192/bjp.bp.107.040113

7. Nock MK, Green JG, Hwang I, et al. Prevalence, correlates, and treatment of lifetime suicidal behavior among adolescents: results from the National Comorbidity Survey Replication Adolescent Supplement. JAMA Psychiatr. 2013;70(3):300-310. doi:10.1001/ 2013.jamapsychiatry.55

8. Sokero P. Suicidal ideation and attempts among psychiatric patients with major depressive disorder; 2006. Available from: https://helda. helsinki.fi/handle/10138/23041. Accessed October 8, 2021.

9. Trivedi MH, Morris DW, Wisniewski SR, et al. Clinical and sociodemographic characteristics associated with suicidal ideation in depressed outpatients. Can J Psychiatry. 2013;58(2):113-122. doi:10.1177/070674371305800209

10. Nobile B, Olié E, Dubois J, Guillaume S, Gorwood P, Courtet P. Characteristics and treatment outcome of suicidal depression: two large naturalistic cohorts of depressed outpatients. Aust N Z J Psychiatry. 2021;000486742110256. doi:10.1177/ 00048674211025697

11. Nobile B, Dubois J, Aouizerate B, et al. Characterization of depressed bipolar patients with current suicidal ideation. Austr NZ J Psychiatr. 2020;55:000486742096374.

12. Lopez-Castroman J, Jaussent I, Gorwood P, Courtet P. Suicidal depressed patients respond less well to antidepressants in the short term. Depress Anxiety. 2016;33(6):483-494. doi:10.1002/da.22473

13. Khan A, Khan SRF, Hobus J, et al. Differential pattern of response in mood symptoms and suicide risk measures in severely ill depressed patients assigned to citalopram with placebo or citalopram combined with lithium: role of lithium levels. J Psychiatr Res. 2011;45 (11):1489-1496. doi:10.1016/j.jpsychires.2011.06.016

14. Ballard ED, Ionescu DF, Vande Voort JL, et al. Improvement in suicidal ideation after ketamine infusion: relationship to reductions in depression and anxiety. J Psychiatr Res. 2014;58:161-166. doi:10.1016/j.jpsychires.2014.07.027

15. Seo H-J, Jung Y-E, Jeong S, et al. Persistence and resolution of suicidal ideation during treatment of depression in patients with significant suicidality at the beginning of treatment: the CRESCEND study. $J$ Affect Disord. 2014;155:208-215. doi:10.1016/j.jad.2013.11.002

16. Batterham PJ, Spijker BAJ, Mackinnon AJ, Calear AL, Wong Q, Christensen H. Consistency of trajectories of suicidal ideation and depression symptoms: evidence from a randomized controlled trial. Depress Anxiety. 2019;36(4):321-329. doi:10.1002/da.22863

17. Madsen T, Van Spijker B, Karstoft K-I, Nordentoft M, Kerkhof AJ. Trajectories of suicidal ideation in people seeking web-based help for suicidality: secondary analysis of a Dutch randomized controlled trial. J Med Internet Res. 2016;18(6):e178. doi:10.2196/jmir.5904

18. van Ballegooijen W, Eikelenboom M, Fokkema M, et al. Comparing factor structures of depressed patients with and without suicidal ideation, a measurement invariance analysis. $J$ Affect Disord. 2019;245:180-187. doi:10.1016/j.jad.2018.10.108

19. Lutz P-E, Courtet P, Calati R. The opioid system and the social brain: implications for depression and suicide. J Neurosci Res. 2018. doi:10.1002/jnr.24269

20. Olié E, Courtet P, Poulain V, Guillaume S, Ritchie K, Artero S. History of suicidal behaviour and analgesic use in community-dwelling elderly. Psychother Psychosom. 2013;82 (5):341-343. doi:10.1159/000350504

21. Calati R, Olié E, Ritchie K, Artero S, Courtet P. Suicidal ideation and suicide attempts in the elderly associated with opioid use and pain sensitivity. Psychother Psychosom. 2017;86(6):373-375. doi:10.1159/000478021
22. Gabilondo AM, Meana JJ, García-Sevilla JA. Increased density of mu-opioid receptors in the postmortem brain of suicide victims. Brain Res. 1995;682(1-2):245-250. doi:10.1016/0006-8993(95) 00333-L

23. Zalsman G, Molcho A, Huang Y, Dwork A, Li S, Mann JJ. Postmortem mu-opioid receptor binding in suicide victims and controls. J Neural Transm (Vienna). 2005;112(7):949-954.

24. Fava M, Memisoglu A, Thase ME, et al. Opioid modulation with buprenorphine/samidorphan as adjunctive treatment for inadequate response to antidepressants: a randomized double-blind placebo-controlled trial. Am J Psychiatry. 2016;173(5):499-508. doi:10.1176/appi.ajp.2015.15070921

25. Yovell Y, Bar G, Mashiah M, et al. Ultra-low-dose buprenorphine as a time-limited treatment for severe suicidal ideation: a randomized controlled trial. Am J Psychiatry. 2016;173(5):491-498. doi:10.1176/ appi.ajp.2015.15040535

26. Kroslak T, Laforge KS, Gianotti RJ, Ho A, Nielsen DA, Kreek MJ. The single nucleotide polymorphism A118G alters functional properties of the human mu opioid receptor. J Neurochem. 2007;103 (1):77-87.

27. Zhang Y, Wang D, Johnson AD, Papp AC, Sadee W. Allelic expression imbalance of human mu opioid receptor (OPRM1) caused by variant A118G. J Biol Chem. 2005;280(38):32618-32624. doi:10.1016/S0021-9258(19)37758-0

28. Peciña M, Love T, Stohler CS, Goldman D, Zubieta J-K. Effects of the $\mathrm{Mu}$ opioid receptor polymorphism (OPRM1 A118G) on pain regulation, placebo effects and associated personality trait measures. Neuropsychopharmacol. 2015;40(4):957-965. doi:10.1038/ npp.2014.272

29. Briand LA, Hilario M, Dow HC, Brodkin ES, Blendy JA, Berton O. Mouse model of OPRM1 (A118G) polymorphism increases sociability and dominance and confers resilience to social defeat. $J$ Neurosci. 2015;35(8):3582-3590. doi:10.1523/JNEUROSCI.4685-14.2015

30. Carver CS, Johnson SL, Kim Y. Mu opioid receptor polymorphism, early social adversity, and social traits. Soc Neurosci. 2016;11 (5):515-524. doi:10.1080/17470919.2015.1114965

31. Bonenberger M, Plener PL, Groschwitz RC, Grön G, Abler B. Polymorphism in the $\mu$-opioid receptor gene (OPRM1) modulates neural processing of physical pain, social rejection and error processing. Exp Brain Res. 2015;233(9):2517-2526. doi:10.1007/s00221015-4322-9

32. Tchalova K, Sadikaj G, Moskowitz DS, Zuroff DC, Bartz JA. Variation in the $\mu$-opioid receptor gene (OPRM1) and experiences of felt security in response to a romantic partner's quarrelsome behavior. Mol Psychiatry. 2019. doi:10.1038/s41380-019-0600-4

33. Way BM, Taylor SE, Eisenberger NI. Variation in the -opioid receptor gene (OPRM1) is associated with dispositional and neural sensitivity to social rejection. Proc Natl Acad Sci USA. 2009;106 (35):15079-15084. doi:10.1073/pnas.0812612106

34. Slavich GM, Tartter MA, Brennan PA, Hammen C. Endogenous opioid system influences depressive reactions to socially painful targeted rejection life events. Psychoneuroendocrinology. 2014;49:141-149. doi:10.1016/j.psyneuen.2014.07.009

35. Hishimoto A, Cui H, Mouri K, et al. A functional polymorphism of the micro-opioid receptor gene is associated with completed suicides. J Neural Transm (Vienna). 2008;115(3):531-536.

36. Nobile B, Ramoz N, Jaussent I, et al. Polymorphism A118G of opioid receptor mu 1 (OPRM1) is associated with emergence of suicidal ideation at antidepressant onset in a large naturalistic cohort of depressed outpatients. Sci Rep. 2019;9(1):2569. doi:10.1038/ s41598-019-39622-3

37. Acikel SB, Eroglu C, Ugras Dikmen A, Kurar E. The association between leptin receptor polymorphism and suicidal behaviour in depressed adolescents. Int J Psychiatry Clin Pract. 2020;24 (2):120-126. doi:10.1080/13651501.2019.1711422 
38. Meyer RE, Salzman C, Youngstrom EA, et al. Suicidality and risk of suicide-definition, drug safety concerns, and a necessary target for drug development: a consensus statement. J Clin Psychiatry. 2010;71 (8):e1-e21. doi:10.4088/JCP.10cs06070ablu

39. Czyz EK, Horwitz AG, King CA. Self-rated expectations of suicidal behavior predict future suicide attempts among adolescent and young adult psychiatric emergency patients. Depress Anxiety. 2016;33 (6):512-519. doi:10.1002/da.22514

40. Gao K, Wu R, Wang Z, et al. Disagreement between self-reported and clinician-ascertained suicidal ideation and its correlation with depression and anxiety severity in patients with major depressive disorder or bipolar disorder. J Psychiatr Res. 2015;60:117-124. doi:10.1016/j.jpsychires.2014.09.011

41. Friedman S, Samuelian J-C, Lancrenon S, Even C, Chiarelli P. Threedimensional structure of the Hospital Anxiety and Depression Scale in a large French primary care population suffering from major depression. Psychiatry Res. 2001;104(3):247-257. doi:10.1016/ S0165-1781(01)00309-2

42. McDowell I. Measuring Health: A Guide to Rating Scales and Questionnaires. Third ed. Oxford, New York: Oxford University Press; 2006:768.

43. Desseilles M, Perroud N, Guillaume S, et al. Is it valid to measure suicidal ideation by depression rating scales? J Affect Disord. 2012;136(3):398-404. doi:10.1016/j.jad.2011.11.013

44. Zisook S, Trivedi MH, Warden D, et al. Clinical correlates of the worsening or emergence of suicidal ideation during SSRI treatment of depression: an examination of citalopram in the STAR*D study. J Affect Disord. 2009;117(1-2):63-73. doi:10.1016/j.jad.2009.01.002
45. Apter A, Kotler M, Sevy S, et al.Correlates of risk of suicide in violent and nonviolent psychiatric patients. AJP. 1991;148 (7):883-887.

46. Lovallo WR, Enoch M-A, Acheson A, et al. Cortisol stress response in men and women modulated differentially by the Mu-opioid receptor gene polymorphism OPRM1 A118G. Neuropsychopharmacology. 2015;40(11):2546-2554. doi:10.1038/npp.2015.101

47. Matsunaga M, Isowa T, Murakami $\mathrm{H}$, et al. Association of polymorphism in the human $\mu$-opioid receptor OPRM1 gene with proinflammatory cytokine levels and health perception. Brain Behav Immun. 2009;23(7):931-935.

48. Courtet P, Giner L, Seneque M, Guillaume S, Olie E, Ducasse D. Neuroinflammation in suicide: toward a comprehensive model. World J Biol Psychiatr. 2016;17(8):564-586. doi:10.3109/15622975.20 15.1054879

49. Troisi A, Frazzetto G, Carola V, et al. Variation in the $\mu$-opioid receptor gene (OPRM1) moderates the influence of early maternal care on fearful attachment. Soc Cogn Affect Neurosci. 2012;7 (5):542-547. doi:10.1093/scan/nsr037

50. Otsuka T, Tomata Y, Zhang S, Tanji F, Sugawara Y, Tsuji I. The association between emotional and instrumental social support and risk of suicide death: a population-based cohort study. J Psychiatr Res. 2019;114:141-146. doi:10.1016/j.jpsychires.2019.04.012
Neuropsychiatric Disease and Treatment

\section{Publish your work in this journal}

Neuropsychiatric Disease and Treatment is an international, peerreviewed journal of clinical therapeutics and pharmacology focusing on concise rapid reporting of clinical or pre-clinical studies on a range of neuropsychiatric and neurological disorders. This journal is indexed on PubMed Central, the 'PsycINFO' database and CAS, and

\section{Dovepress}

is the official journal of The International Neuropsychiatric Association (INA). The manuscript management system is completely online and includes a very quick and fair peer-review system, which is all easy to use. Visit http://www.dovepress.com/testimonials.php to read real quotes from published authors. 